\begin{tabular}{|l|l} 
Universidad \\
de La Laguna \\
Facultad de Derecho
\end{tabular}

Grado en Relaciones Laborales

Facultad de Derecho

Universidad de La Laguna

Curso Académico 2015/2016

Convocatoria: SEPTIEMBRE

\title{
REPRESENTATIVIDAD SINDICAL
}

\section{Union Representation}

Realizado por la alumna Virginia Pérez Romero

Tutorizado por el profesor D.Brais Columba Iglesias Osorio

Área de conocimiento: Derecho Del Trabajo y de la Seguridad Social 


\begin{abstract}
Union representation arises in the historical context of the 20 s, in which they grow and trade unions are structured. In this paper I try to analyze its meaning, participants subjects and their chronological development from its inception to the present, based both on the problems of concentration and competition between unions and the ideological and political struggle between different groups.

That period of historical evolution is a fundamental change in the concept of representation as unions have passed since the representation of members of the notion of representation, which has favored the political and institutional role of trade unions.
\end{abstract}

Finally I analyze the current situation and the loss of credibility that these unions are facing, analyzing their causes and consequences.

\title{
RESUMEN
}

La representatividad sindical surge en el contexto histórico de los años 20, en el cual crecen y se estructuran las organizaciones sindicales. En este trabajo intentaré analizar su significado, los sujetos participantes y su evolución cronológica desde su origen hasta la actualidad, basándome tanto en los problemas de concentración y competencia entre las distintas organizaciones sindicales como en los de lucha ideológica y política entre los distintos grupos.

Ese período de evolución supone un cambio histórico fundamental en el concepto de representatividad ya que los sindicatos han pasado desde la representación de afiliados a la noción de representatividad, que ha favorecido el papel político-institucional de los sindicatos.

Por último analizo el panorama actual y la pérdida de credibilidad a la que se enfrentan estas organizaciones sindicales, analizando sus causas y consecuencias. 


\section{ULL L}

Índice

1. Introducción. .4

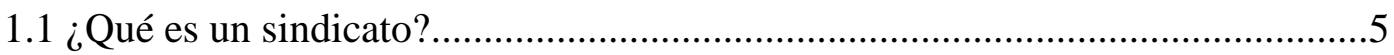

1.2 Historia de los sindicatos en España............................................................

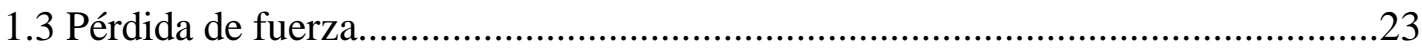

2. Representatividad sindical.........................................................................................28

2.1 Sindicatos más representativos a nivel de Estado...............................................28

2.2 Sindicatos más representativos a nivel de Comunidad Autónoma........................29

2.3. Sindicatos más representativos en un ámbito específico........................................30

2.4 Conflictividad surgida en la interpretación de los conceptos..................................31

3. Funciones de los sindicatos en relación a su representatividad...........................34

4. Especial mención a la figura del delegado sindical en contraposición al enlace

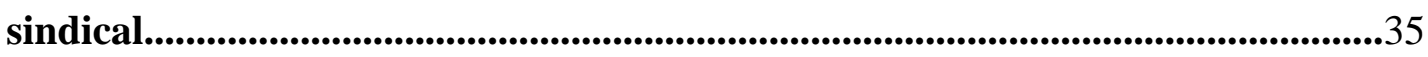

5. Conclusiones......................................................................................................................4

6. Bibliografía........................................................................................................................4 


\section{INTRODUCCIÓN}

El trabajo que a continuación se presenta tiene como tema fundamental la Representatividad Sindical. El objetivo de este estudio es realizar una aproximación al sistema de representación sindical en España. Se pretende estudiar la representación sindical, la participación de los trabajadores y el nivel de representatividad de los sindicatos en la actualidad, para obtener un mayor conocimiento de la situación real del sindicalismo en la historia reciente del constitucionalismo y la situación de crisis actual. Para adentrarnos en este mundo, hay que tener en cuenta la lucha a la que han sido sometidas muchas personas para que hoy tengamos ciertos privilegios que antes no estaban presentes en las relaciones laborales y que la actual sociedad capitalista está destruyendo con sus políticas neoliberales. Se ha producido un gran debilitamiento en el poder sindical y lo que persiguen este tipo de políticas es la segmentación de la sociedad y la concentración de la riqueza en manos de unos pocos.

Hay que tener en cuenta que las tasas de afiliación en España son bajas y se asientan sobre todo en trabajadores de la Administración Pública y en las grandes empresas, en cambio en la empresa pequeña la presencia sindical es bastante escasa, por no decir inexistente. La representatividad es una construcción social que favorece las condiciones asociativas y no la afiliación en pequeñas empresas.

La metodología utilizada han sido referencias bibliográficas, tablas estadísticas... a través de las que analizamos la situación del sindicalismo español y sus repercusiones en la sociedad actual debido al continuo cambio del mercado de trabajo y al ineficiente papel de los sindicatos y de la sociedad en general para hacer frente a esta realidad. El análisis de los resultados obtenidos a través de diferentes fuentes, nos ha proporcionado un mayor conocimiento y una visión lo más clara y real posible sobre la situación que estamos viviendo. ${ }^{1}$

\footnotetext{
${ }^{1}$ Véase Alós, R, Beneyto, P, Jódar, P, Molina, O, Vidal, S, (2015), "La Representación Sindical en España", Fundación $1^{\circ}$ de Mayo, p.17 en: http://www.1mayo.ccoo.es/nova/files/1018/LibroRepresentacion.pdf
} 


\section{ULL L}

La Representatividad sindical surge en el contexto histórico de los años 20, en el cual crecen y se estructuran las organizaciones sindicales. Entonces, existían problemas de concentración y competencia; de lucha ideológica y política entre las distintas organizaciones sindicales. El proceso de evolución de este concepto ha favorecido el creciente papel político-institucional de los sindicatos. La relevancia de abordar este tema nos lleva a una cuestión fundamental:

\section{1 ¿Qué es un sindicato?}

Los sindicatos en España están reconocidos en la Constitución de 1978, en la que se dice que el sindicato es "la organización que defiende los intereses de los trabajadores" — según la Real Academia Española, es la asociación de trabajadores constituida para la defensa y promoción de intereses profesionales, económicos o sociales de sus miembros-

Lista de organizaciones sindicales de España

- Agrupación de los Cuerpos de la Administración de Instituciones Penitenciarias (ACAIP)

- Alternativa Sindical de Trabajadores (AST)

- Asociación Agraria Jóvenes Agricultores (ASAJA)

- Asociación Nacional de Profesionales de la Enseñanza (ANPE)

- Central Sindical Independiente y de Funcionarios (CSI-F)

- Comisiones Obreras (CC.OO.)

- Confederación de Sindicatos de Trabajadores de la Enseñanza (STEs)

- Confederación General del Trabajo (CGT)

- Confederación Intersindical Galega (CIG)

- Confederación Nacional del Trabajo (CNT)

- Coordinadora de Organizaciones de Agricultores y Ganaderos (COAG)

- Coordinadora Obrera Sindical (COS)

- Euskal Herriko Nekazarien Elkartasuna (EHNE) 
- Eusko Langileen Alkartasuna-Solidaridad de los Trabajadores Vascos (ELASTV)

- $\quad$ Ezker Sindikalaren Konbergentzia (ESK)

- Intersindical - Confederació Sindical Catalana

- $\quad$ Langile Abertzaleen Batzordeak (LAB)

- $\quad$ Sindicato Andaluz de Trabajadores (SAT)

- $\quad$ Sindicato de circulación ferroviario $(\mathrm{SCF})$

- Sindicato de Empleados de la Caja de Ahorros y Pensiones de Barcelona (SECPB)

- $\quad$ Sindicato de Enfermería (SATSE)

- Sindicato de Ingenieros Técnicos e Ingenieros en Informática (SITIC)

- $\quad$ Sindicato de Médicos de Asistencia Pública (SIMAP)

- $\quad$ Sindicato de Trabajadores de Comunicaciones (STC)

- Sindicato Labrego Galego (SLG-CC.LL.)

- $\quad$ Sindicato Obrero Canario (SOC)

- Confederación Española de Policía (CEP)

- Sindicato Unificado de Policía (SUP)

- $\quad$ Sindicato Unitario $(\mathrm{SU})$

- $\quad$ Solidaridad Obrera (SO)

- Unió de Pagesos

- Unión de Pequeños Agricultores y Ganaderos (UPA)

- Unión General de Trabajadores (UGT)

- Unión Nacional de Trabajadores (UNT)

- Unión Sindical Obrera (USO)

Los sindicatos pueden ser definidos como una estructura de control compensadora, que restringe y limita el poder empresarial. Un sindicato es básicamente un instrumento y un medio de poder colectivo para controlar las condiciones de empleo. Esta concepción nos remite a la idea del sindicato como organización que a través de la acción y del derecho colectivo trata de compensar la asimetría de los individuos frente al contrato de trabajo 
(Martin Artiles 2003) ${ }^{2}$. Sin embargo, además de una organización, los sindicatos han sido también históricamente, y lo son todavía, un movimiento social de defensa económica de los trabajadores.

Asimismo, la Ley Orgánica de Libertad Sindical en su artículo 1, al igual que la constitución española en su artículo 28, establece que "todos los españoles tienen derecho a sindicarse libremente para la defensa de sus intereses económicos y sociales". Por tanto las personas que libremente pueden pertenecer a un sindicato son: los trabajadores asalariados y funcionarios; los trabajadores en paro; los jubilados o personas incapacitadas; y los trabajadores por cuenta propia.

Pero no todas las personas pueden pertenecer a un sindicato ya que quedan excluidos de pertenecer a un sindicato: los miembros de las fuerzas armadas del estado; y los jueces magistrados y fiscales en activo: no pueden pertenecer a un sindicato pero si asociarse ya que existe la Unión de Jueces para la Democracia.

En definitiva, los sindicatos surgen a finales del siglo XIX ${ }^{3}$ y se los puede definir como un grupo de trabajadores profesionales que se agrupan con el fin de defender sus intereses económicos, sociales y laborales frente a aquellas personas, dueñas de los factores productivos (empresarios) y que ostentan el poder (autoridades).

\section{$\underline{\text { Clases de sindicatos }}$}

Los sindicatos independientemente de su clasificación, todos tienen la misma finalidad: la defensa del trabajo y de los trabajadores para intentar mejorar las condiciones laborales: salarios más justos, mejores jornadas laborales, mejor protección por desempleo, etc. Podemos distinguir varios tipos de clasificaciones:

Atendiendo a sus miembros: estos sindicatos se clasifican en función de la empresa, profesión, oficio o sector económico o de actividad al que pertenece el trabajador:

\footnotetext{
${ }^{2}$ Véase Köhler,H-D y Martín Artiles, A (2007). Manual de la sociología del Trabajo y de las Relaciones laborales. Madrid, Delta.. Capítulo 12, $1^{\circ}$ parte, cit., p. 426

${ }^{3}$ Baylos A, Las relaciones laborales en España 1978-2003. Desde la Constitución hasta nuestros días, p. 237
} 
1. Sindicatos Industriales: Este tipo de sindicato agrupa a todos los trabajadores de una determinada industria sin tener en cuenta cual sea su puesto de trabajo, especialización u oficio en esa industria.

2.Sindicatos profesionales o de oficio: son todos aquellos trabajadores de un mismo oficio o profesionalidad independientemente del tipo de industria en el que se encuentren.

3. Sindicato de empresa: agrupa a todos aquellos trabajadores de una misma empresa independientemente del puesto de trabajo que en ella desempeñen.

4. Sindicato interempresa: formados por todos aquellos trabajadores que están a las órdenes de más de un empleador.

5. Sindicato general: agrupa a todo tipo de trabajadores independientemente de cuál sea su profesión, oficio o puesto de trabajo o sector de la industria o actividad en el que se encuentre.

Atendiendo a su ámbito territorial: este sindicato agrupa a todos aquellos trabajadores pertenecientes a un mismo sector de actividad en función del ámbito geográfico: internacional, nacional, comunidad autónoma, provincial y local en el que actúa. Estos son:

1. Sindicato internacional: unión internacional de diversas corrientes sindicales para luchar contra una causa común que es la defensa del trabajo y de la clase trabajadora. Este tipo de sindicatos suelen unirse mediante sectores de actividad.

2. Sindicato nacional: este tipo de sindicatos se agrupan por sectores de actividad y que se dan solo a nivel nacional.

3. Sindicato de comunidad autónoma: son agrupaciones de trabajadores por sector de actividad que se dan en toda una comunidad autónoma.

4. Sindicato provincial: sindicatos que agrupan a personas de un mismo sector de actividad que solo actúan en una determinada provincia.

5. Sindicato local: agrupan a todos aquellos trabajadores de un determinado sector industrial que se dan en una determinada ciudad o pueblo. 
Atendiendo a su acción política: son dos tipos de sindicatos que se clasifican en función de la labor o acción que defienden, son:

1. Sindicatos reformistas libres: son aquellos que en lugar de tener una acción defensiva de los derechos y condiciones laborales de los trabajadores, defienden las acciones del sistema político

2. Sindicatos revolucionarios: es un sindicato radicalizado que defiende la autonomía de la lucha de la clase trabajadora frente al estado y los empleadores, es decir, que se opone al parlamentarismo democrático y a la sujeción de un trabajador y su lucha a un partido político.

Atendiendo a su representatividad: este tipo de sindicatos se clasifican en función de los delegados de personal, miembros de comités de empresa o representantes de trabajadores que hayan obtenido en las elecciones sindicales en el caso de los sindicatos más representativos estatalmente, en comunidades autónomas o simplemente representativo, y en función del número de afiliados y federados en el caso de los sindicatos más representativos por irradiación. Estos sindicatos son:

1. Sindicato más representativo estatalmente: son los que han obtenido el $10 \%$ de los delegados de personal, miembros de los comités de empresa y órganos de las administraciones públicas en las elecciones sindicales a nivel estatal.

2. Sindicatos más representativos en las comunidades autónomas: obtienen el 15\% de los representantes de los trabajadores en las comunidades autónomas y cuentan con un mínimo de 1500 representantes siempre que no estén federados y sean a nivel estatal.

3. Sindicatos más representativos por irradiación: son los afiliados, federados o confederados a una organización sindical más representativa de ámbito estatal o de comunidad autónoma y son los que cuentan con la mayor representatividad. Solo pueden actuar en el ámbito territorial o funcional que les corresponda.

4. Sindicato suficiente o simplemente representativo: obtienen en un ámbito funcional y territorial el $10 \%$ de los delegados de personal y miembros de comités de empresa siempre que no alcancen la condición de más representativos. S 


\section{UIII Uninerisiad de La Laguna \\ Facultad de Derecho}

\subsection{Historia del sindicalismo español}

\subsubsection{Cuestión social y el movimiento obrero: antecedentes.}

La cuestión social es el proceso de sustitución de trabajo humano por las máquinas y sus consecuencias aparejadas (el incremento de los rendimientos, división del trabajo, concentraciones urbanas) originaban un excedente de mano de obra propicio para la explotación. El intercambio de trabajo por salario estaba sometido al igual que cualquier otra relación económica, a la ley de la oferta y la demanda de los bienes objeto de transacción (trabajo y salario). Por un lado la oferta de trabajo no dejaba de crecer como consecuencia de la destrucción del empleo derivada de la generalizada industrialización de la producción, por otra parte la demanda de trabajo controlada por el empresario era cada vez más reducida por la misma razón que la oferta era cada vez mayor. El empresario podía actuar libremente al amparo de las leyes del mercado que determinaban la cantidad y el precio del bien objeto de cambio. El empresario podía así libremente disponer de condiciones de trabajo malas (tiempos de trabajo prolongados y salarios reducidos) sabiendo que serían aceptadas por uno u otro individuo de una superpoblada oferta de trabajo. Predomina la voluntad del empresario en la fijación de las condiciones contractuales que no dudaría en ejercer sin reparos en favor de su máximo beneficio. Las terribles consecuencias del maquinismo y de la exaltación capitalista de los principios liberales habrían de conducir a jornadas de trabajo agotadoras, salarios de hambre, condiciones laborales precarias, y explotación cualificada del trabajo de la mujer y de los menores (llamadas medias fuerzas). El régimen del truck consiste en el pago de los bajos salarios en especies distintas del dinero o en vales canjeables por determinados productos únicamente en los establecimientos propiedad del empresario y en los que a nivel de precio eran muy superiores a los habituales y esto reducía al mínimo el poder adquisitivo de los trabajadores. Se había llegado a la explotación sistemática del proletariado industrial.

La noción de movimiento obrero se construye sobre tres elementos:

1. La formación de la clase obrera a partir de las relaciones de producción capitalista cuyo punto de partida es la separación entre el trabajador y los instrumentos o medios de producción. 
2. La aparición en el seno de este grupo social una conciencia de clase, y esta convicción de clase social diferenciada no basta por sí sola para la emergencia de un proletario militante.

3. Se ha de producir así, una toma de conciencia adicional por parte de la clase obrera. La movilización consiguiente contra el orden económico burgués a través de organizaciones, políticas o sindicales constituye propiamente la noción de movimiento obrero y es la serie de instituciones en que se agrupan los trabajadores y todos aquellos que optan por militar a su lado, conscientes unos y otros de su solidaridad y de la unidad que para ellos tiene organizarse a fin de precisar sus objetivos comunes y de perseguir su realización.

\subsubsection{Nacional-sindicalismo y Organización sindical en el Estado franquista.}

El nacional-sindicalismo es el "movimiento sindical" patrocinado por las autoridades franquistas.

Se prohíben los sindicatos y los partidos políticos, y se acoge el nacional-sindicalismo.

Este movimiento surge realmente en la Segunda República, y consiste en un movimiento totalitario, antimarxista y fascista. Lo que pretende defender es que no hay libertad sindic ${ }^{4}$ al, porque el Estado tiene un "organigrama sindical" que se encarga de resolver los problemas colectivos.

1931.- Aparecen las Juntas Ofensivas Nacional Sindicalista (JONS).

1934.- JONS se une a la Falange Española, se une un sindicato y un partido político.

1938.- Se aprueba el FUERO DEL TRABAJO (primera ley fundamental). En el que se acoge el nacional-sindicalismo, con lo cual ya se habla de un sindicato vertical español.

1940.- Se crea la OSE, la Organización Sindical Española (sindicato vertical).

\footnotetext{
${ }^{4}$ Köhler, H-D (1995), "El movimiento sindical en España. Transición democrática, regionalismo, modernización económica", Madrid, Fundamentos, p. 35
} 
A partir de los años 40 el franquismo se caracteriza por el "carácter evolutivo de la administración franquista", esto quiere decir que se produce cierta apertura. Esto afecta a la OSE, que irá modernizando y "democratizando". En esta época el Estado monopoliza la producción normativa sindical (los convenios colectivos son desarrollados por el Estado), creando las Reglamentaciones del Trabajo.

\subsubsection{La reconstrucción del movimiento sindical.}

El movimiento sindical se empieza a reconstruir desde el comienzo de la dictadura, pero desde la clandestinidad.

A lo largo de los años 40 se sabe que ciertas huelgas que se produjeron en España, fueron convocadas por dirigentes en el extranjero, sobre todo UGT.

En los años 50 aparece una nueva forma de organización sindical, son las llamadas Comisiones Obreras. Cuando se crean no son sindicatos, son una especie de movimientos obreros organizados, con una precaria estructura organizativa, una mínima organización y un coordinador de comisiones obreras, pero no se asemejan a un sindicato.

A lo largo de los años 60 estas Comisiones van poco a poco haciéndose notar y se empiezan a crear con carácter permanente. Se crea la USO (Unión Sindical Obrera 1966) como organización de clase, independiente de los partidos políticos.

En 1972 hay una reconstrucción de la UGT.

En 1975 se crea la Confederación Sindical de Comisiones Obreras, que se crearía como sindicato.

\subsubsection{Transición política y "reforma sindical".}

La transición política española es el proceso político por el que España pasó de un sistema político dictatorial a un régimen político liberal democrático con: Constitución, elecciones libres por sufragio universal, derechos y libertades, multipartidismo, etc. 


\section{ULL}

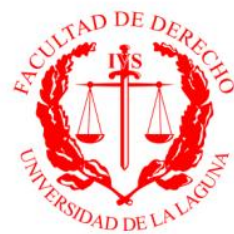

Se inicia tras la muerte de Franco, en 1975. En 1976 hay un intento de unificación global, se crea la Coordinadora de Organizaciones Sindicales, que tendrá una muy corta vida (unos pocos meses). En este mismo año comienza lo que se llamó la "reforma sindical", que consiste en la desmantelación de la OSE por un decreto de 1976 y se aprueba la ley 19/1977 de 1 de abril, con la cual vuelve a ser posible, en España, crear sindicatos dentro de la ley.

En 1977 se creó la Ley de Reforma política, tuvo lugar las primeras elecciones democráticas y la legalización de centrales sindicales y partidos políticos.

En 1978 se firma la Constitución Española actual.

La transición se inicia con la proclamación de Juan Carlos como rey. Para ello debe jurar los Principios Fundamentales del Movimiento Nacional, lo hizo el 22/11/75. Así estaba previsto desde que Franco lo había nombrado su sucesor en 1969. Pero el camino seguido por el rey iba a ser muy distinto del imaginado por el dictador y sus fieles. ${ }^{5}$

Los cambios socioeconómicos y culturales ocurridos a partir de los 60 iban contra los principios e intereses de la dictadura. España es un país económica y socialmente moderno, pero políticamente atrasado. Dentro del Régimen existieron dos tendencias:

- Tecnócratas: inmovilistas en lo político, conciben el postfranquismo como una monarquía autoritaria.

- Aperturistas: pretenden hacer evolucionar políticamente al régimen.

En los años 60 el Régimen continuó con su actitud transformadora respecto a los regímenes occidentales, pero sin modificar nada su estructura política:

- Mejoras en las prestaciones sociales: Ley de Bases de la Seguridad Social

- TOP, los civiles sustituyen a los militares en el enjuiciamiento de delitos políticos.

- Ley de Prensa de 1966, fin de la censura previa.

- Ley de Libertad Religiosa de 1967, libre ejercicio del culto.

- Ley de Educación de 1970, escolarización obligatoria hasta los 14 años.

\footnotetext{
${ }^{5}$ Idem, p. 36
} 
Los tecnócratas, inmovilistas, se hacen con el control del poder en 1969, con Carrero Blanco como presidente del Gobierno.

El 14 de febrero de 1974 el presidente Arias Navarro anunció una apertura política del Régimen, es el "Espíritu del 12 de febrero". Prometió innovaciones como permitir la elección de alcaldes, reformas sindicales y una ley sobre "asociaciones políticas".

Pronto se vio que la evolución prometida no se daba. La oposición organizaba protestas y la respuesta del régimen fue la represión: fusilamientos, detenciones masivas, leyes antiterroristas, cierre de revistas, etc. Dentro del régimen, los inmovilistas, "el bunker", no admitían la menor reforma y actuaron contra los sospechosos de izquierdismo. ${ }^{6}$

Tras la muerte del dictador en España se dan tres grandes tendencias políticas:

- Inmovilista: miembros del "bunker", desean un franquismo sin Franco. Falangistas, cúpula del Ejército y sindicalismo vertical.

- Reformista: los aperturistas del franquismo como Fraga, Areilza o Suárez. También los opositores moderados al Régimen. Proponen una transición más o menos suave.

- Rupturista: los opositores radicales: izquierda clásica y nueva (PSOE, PCE, CCOO...)

El Rey Juan Carlos, en su discurso de coronación, apuntaba sus intenciones reformistas:

- Nombramiento de T. Fernández Miranda al frente de las Cortes y del Consejo del Reino.

- Los contactos con la oposición y líderes extranjeros para conseguir apoyo para los cambios.

- Concesión de un indulto

Para tranquilizar al franquismo, nombra a Arias Navarro presidente del gobierno, con la idea de recuperar el "Espíritu del 12 de Febrero". En su equipo había aperturistas como Fraga, Areilza, Suárez o Martín Villa.

\footnotetext{
${ }^{6}$ Ibídem
} 
Arias Navarro no inicia la esperada reforma política. Pasa el tiempo y no concede ni amnistía, ni libertad sindical, ni derecho de huelga... Además reprime con dureza cualquier tipo de oposición a la autoridad. En un contexto de gran conflictividad sociolaboral, el gobierno reprime violentamente las protestas. Es el caso de 5 muertos en Vitoria en el desalojo de una iglesia en marzo de 1976.

La oposición política liderada por PCE y PSOE se une creando la "Platajunta". Pide un gobierno provisional y Cortes constituyentes. La calle pide libertad, amnistía y autonomía. El rey, públicamente critica al presidente y lo hace dimitir en julio de 1976.

\section{Evolución de la democracia en España}

El rey nombró presidente a Adolfo Suárez . Fue una jugada arriesgada, Suárez y su gobierno de PNN (profesores no numerados, equivalentes a inexpertos) no fue bien recibido por la oposición que se esperaba a J. Mª . Areilza. Parecía un paso atrás.

En un contexto de crisis económica y conflictividad política, Suárez puso hábilmente en marcha una estrategia de reforma pactada "paso de ley a ley", de las leyes del Franquismo a las democráticas. El medio fue la Ley para la Reforma Política redactada por Fernández Miranda, propone elegir por sufragio universal unas nuevas Cortes bicamerales.

Las Cortes franquistas hace promesas como que no se pedirán responsabilidades por la dictadura, no se legalizará el PCE (Partido Comunista de España) y se hará la reforma utilizando las leyes vigentes. Las Cortes aprobaron la LRP por 425 votos a favor, 59 votos en contra y 13 abstenciones.

El 15 de diciembre de 1976 se celebró el referéndum sobre la LRP. El sí ganó por aplastante mayoría, los inmovilistas que pedían el no apenas tuvieron eco. La izquierda que había defendido la abstención debió reconsiderar su actuación.

El paso siguiente fue la legalización de los partidos políticos mediante Decreto-Ley en febrero de 1977 que dejaba fuera a los partidos miembros de alguna organización internacional que defienda la imposición de un Estado totalitario. Ello dejaba fuera al PCE. Fue una decisión arriesgada por la oposición del Ejército, pero Suárez la consideró un requisito para dar credibilidad a la democracia española. Se inscriben más de 200 
partidos políticos y el 15 de abril se convocan elecciones a Cortes Constituyentes. Surgen partidos nuevos:

- UCD: dirigido por A. Suárez. Une a democristianos, liberales y socialdemócratas (de centro).

- AP: dirigido por M. Fraga, compuesto por antiguos franquistas (derecha).

Salen de la clandestinidad antiguos partidos:

- PSOE y PCE: entre otros, en la izquierda.

- PNV (derecha) y ERC (izquierda), entre los nacionalistas.

A pesar de los obstáculos que suponía la situación económica y la actuación de grupos violentos, el proceso democratizador siguió adelante. Las elecciones de junio de 1977 dieron el triunfo por mayoría simple de UCD. Se iniciaba el PERIODO CONSTITUYENTE que abarcará desde junio de 1977 a diciembre de 1978.

RETOS del primer gobierno y parlamento democráticos:

- Hacer frente a la crisis económica.

- Crear una Constitución. El nuevo marco político.

- Atender las reivindicaciones de las nacionalidades históricas.

Lo más notable del periodo fue la capacidad de Suárez para crear un clima de CONSENSO, conseguir que los intereses partidistas quedaran al margen, la prioridad era consolidar la democracia, clave del éxito de la Transición.

\section{El consenso económico, los Pactos de la Moncloa.}

Se produce en un contexto de grave crisis económica mundial. En España: PIB estancado, inflación, paro y déficit público elevados y al alza; una fiscalidad inadecuada para hacer frente a la crisis.

Partidos, sindicatos y organizaciones empresariales negocian para mejorar la economía y apuntalar la democracia. Se firman en octubre de 1977, los PACTOS DE LA 
MONCLOA, cuyos objetivos eran reducir la inflación, repartir los costes de la crisis y las medidas llevadas a cabo fueron:

- Devaluación de la peseta.

- Reducción gasto público

- Reforma tributaria: 1977 Impuesto Extraordinario sobre el Patrimonio; 1978 Impuesto sobre la renta de las personas físicas- IRPF- (básicos para desarrollar el Estado del bienestar).

- Contención salarial.

- Plan para la creación de empleo.

Estas medidas detuvieron la contracción del PIB, control de la inflación y el déficit exterior, pero no del paro.

\section{CONSTITUCIÓN DE 1978}

En 1978 se crea la Constitución Española actual, cuyos rasgos principales fueron ${ }^{7}$ :

- Estado de derecho.

- Amplia declaración de derechos y libertades, inspirada en la Declaración Universal de los Derechos Humanos.

- Monarquía parlamentaria, el rey es el Jefe del Estado sin poder ejecutivo.

- División de poderes: 1) Cortes bicamerales, elegidas por sufragio universal, con poder legislativo 2) Gobierno, poder ejecutivo 3) Tribunales, poder judicial 4) T.Supremo, máxima instancia judicial 5) Tribunal Constitucional 6) Defensor del pueblo

- Descentralización del Estado: posibilidad de constituir comunidades autónomas.

Tras ser aprobada la Constitución, UCD (Unión de Centro Democrático) gana nuevamente en las elecciones de 1979. La labor principal que se plantea el gobierno es

\footnotetext{
${ }^{7}$ La España Democrática, "La transición política. La constitución de 1978 y el Estado de las Autonomías" en: http://www.historiasiglo20.org/HE/16a-2.htm
} 


\section{ULL}

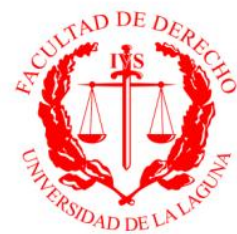

la construcción del Estado de Autonomías, se aprueban los Estatutos Vascos y Catalán y el Estatuto de los Trabajadores.

UCD, el partido de A. Suárez comienza a resquebrajarse por ambiciones de los diferentes integrantes y divisiones internas respecto al desarrollo legislativo: divorcio, descentralización del Estado, reforma fiscal... La oposición hace su papel, llegando a presentar una moción de censura que no prosperó. Suárez termina presentando su dimisión el 29/01/1981.

La andadura inicial de la democracia fue complicada por la amenaza terrorista y golpista y el recrudecimiento de la crisis económica (subida del petróleo). Se produjo un desgaste de UCD por divisiones internas y hubieron amenazas de golpe de estado por parte del Ejército.

Finalmente fue reforzada tras el fracaso del Golpe de Estado del "23 F" de 1981, durante la investidura de Calvo Sotelo. La intervención del rey fue vital para detener el golpe y en las elecciones del 28 de octubre de 1982, el PSOE triunfó por mayoría absoluta.

Hay que hacer especial hincapié en la evolución que se produjo en la afiliación sindical en España que se corresponde con el inicio de la transición política de la dictadura a la democracia (1975-1978), donde se registra una tendencia al alza en la afiliación, estimada en torno al $18 \%$ de la población asalariada. Este crecimiento tiene explicaciones políticas, asociadas a una importante conflictividad laboral y al clima eufórico de la transición, además todavía el impacto de la crisis del petróleo (1973 y 1979) no tiene efectos negativos y significativos sobre el empleo. Sin embargo se trata de un período de fuerte división sindical y con un gran enfrentamiento por la hegemonía sindical entre CCOO y UGT, que corre también paralelo a la lucha por la hegemonía política en el seno de la izquierda, entre el PCE y el PSOE. ${ }^{8}$

Un segundo período (entre 1979 y 1985) se caracteriza por una fuerte pérdida de la afiliación sindical. Ésta decrece en medio de una fuerte crisis económica y un clima sindical depresivo que dan lugar a: un drástico aumento del desempleo, reestructuración

\footnotetext{
${ }^{8}$ Véase Köhler,H-D y Martín Artiles, A (2007). Manual de la sociología del Trabajo y de las Relaciones laborales. Madrid, Delta.. Capítulo 12, $1^{\circ}$ parte, p.462
} 
industrial, reducción de plantilla, reducción del poder adquisitivo de los salarios y políticas de pacto para contener la inflación. Sin embargo, en este período los sindicatos logran la introducción de la LOLS 1985, ley que favorece la concentración de la representatividad electoral en torno a los grandes sindicatos: CCOO y UGT.

En un tercer período, (entre 1986 y 1990) de nuevo vuelve a crecer moderadamente la afiliación $(+0,5 \%)$, ahora estimulada por el crecimiento del empleo (aunque sea temporal) y la mejora de las expectativas económicas. En este período rebrota la conflictividad laboral, mejora el empleo y el poder adquisitivo de los salarios.

Y en cuarto lugar (entre 1990 y 2003) se puede observar un período de crecimiento importante del número de afiliados $(+7,7 \%$ en 1995 y $+3,8$ en el 2000 y $+11,8$ en el 2003). No obstante las tasas netas de afiliación aparecen relativamente estables desde 1990. Es curioso que durante la crisis y destrucción del empleo entre 1991 y 1994 no retrocede la afiliación sindical. Las razones estriban en la brevedad de la crisis y en la rápida recuperación del empleo y de los salarios a partir de 1995. Sin embargo la temporalidad del empleo a entorpecido este crecimiento. A pesar de todo, los sindicatos españoles se han modernizado en las dos últimas décadas, se han abierto a nuevos sectores de actividad, como es el caso de los servicios. La imagen de los sindicatos compuestos por afiliados de baja cualificación es del pasado, los sectores tradicionales han venido perdiendo peso en la afiliación. El peso lo ganan otros sectores como Administración Pública, Sanidad, Enseñanza, con mayor nivel de estudios. ${ }^{9}$

\section{Estudio del artículo 7 de la Constitución}

La importancia que nuestra Constitución confiere a los sindicatos y a las asociaciones empresariales en el marco del Estado social y democrático de Derecho, ha llevado al constituyente a referirse al tema sindical en varios artículos de nuestra Norma Fundamental. Dentro del Título Preliminar, el artículo 7 CE consagra su papel como organizaciones básicas para la defensa y promoción de los intereses económicos y sociales. En conexión con el anterior, el art. 28.1 CE formula el derecho de libertad

\footnotetext{
${ }^{9}$ Ibídem
} 
sindical como un derecho fundamental (situado en la Sección $1^{\text {a }}$ del Capítulo II del Título I), recogiendo en su párrafo segundo el derecho de huelga.

A lo largo del Texto constitucional se hace referencia a la participación de los sindicatos y las asociaciones empresariales en la vida económica y social (art. 37.1 CE sobre el derecho de autonomía colectiva; la participación en la Seguridad Social y en los organismos públicos cuya función afecte a la calidad de vida o bienestar general (art. 129.1 CE); la participación en la empresa (art. 129.2 CE); el derecho a adoptar medidas de conflicto colectivo (art. $37.2 \mathrm{CE}$ ), y la participación de los sindicatos y de las asociaciones empresariales en la planificación económica (art. 131.2 CE).

En cuanto al precedente más interesante de nuestro constitucionalismo histórico conviene recordar el art. 39 de la Constitución española de 1931, que establecía: "los españoles podrán asociarse o sindicarse libremente para los distintos fines de la vida humana, conforme a las leyes del Estado", con el requisito tanto en el caso de asociaciones como de sindicatos de inscribirse en el Registro público correspondiente.

La discusión del precepto durante su tramitación se centró básicamente en dos cuestiones. En primer lugar, el posible contenido corporativista del artículo ante la conveniencia de eliminar reminiscencias o derivaciones de este carácter. El otro gran tema fue el debate en torno a los colegios profesionales, que estaba incluido en el mismo artículo del Anteproyecto de Constitución que contenía la referencia a los sindicatos y organizaciones empresariales, y que fue posteriormente separado y reconocido en el art. 36 del texto constitucional. En ningún caso se discutió y aclaró el sentido o justificación del artículo dentro del Título Preliminar, y, ante el consenso general de su conveniencia, tampoco se planteó su supresión.

Por otro lado, la normativa de nuestro ordenamiento jurídico interno que desarrolla el derecho de libertad sindical ha encontrado una variada fuente en distintos preceptos y normas del ámbito internacional, que han incidido sobre una configuración del art. 7 CE: 
- La Declaración Universal de Derechos Humanos de 1948.

- El Convenio Europeo para la Protección de los Derechos Humanos y Libertades $\begin{array}{lllll}\text { Fundamentales } & \text { de } & \text { Roma } & \text { de }\end{array}$

- El Convenio Núm. 87/1948 de la Organización Internacional del Trabajo (OIT) $\begin{array}{llllll}\text { - } & \text { El } & \text { Convenio } & \text { de } & \text { la } & \text { OIT }\end{array}$

- La Carta Social Europea del Consejo de Europa de 1961

Por otro lado, en relación a la exégesis y contenido del art. 7 CE podemos señalar las siguientes características:

$1^{\circ}$. Situar, en primer lugar, a los sindicatos de trabajadores y las asociaciones empresariales como importantes pilares dentro del Estado social y democrático de Derecho al ocupar un papel de "organismos básicos" en el sistema político.

Si entendemos la acción sindical, como aquella acción que representa y defiende los intereses de los trabajadores, podemos afirmar que en nuestro ordenamiento existe un sistema sindical dual en el que dicha acción sindical puede ser ejercida no sólo por el sindicato sino también por el comité de empresa, aunque no son dos sujetos idénticos, dado que el art. 7 CE constitucionaliza el sindicato pero no el comité de empresa.

$2^{\circ}$. En segundo lugar, la formalización de sindicatos y organizaciones empresariales recogidas en el art. 7 CE, le asigna la "defensa y promoción de los intereses económicos y sociales que les son propios", ha llevado a considerarlas como asociaciones "de relevancia constitucional".

Precisamente porque entre las funciones de los sindicatos se encuentra la defensa y promoción de los intereses económicos y sociales de los trabajadores, en aras de la libertad sindical, se comprende que el ordenamiento jurídico proteja el derecho de los individuos a fundar sindicatos y a afiliarse a los de su elección.

$3^{\circ}$. En tercer lugar el art. 7 CE no sólo consagra el derecho de libertad sindical, sino que se ocupa de declarar que tanto su creación como el ejercicio de su actividad son libres dentro del respeto a la Constitución y a la ley, fijando como límite a la misma la exigencia de una estructura interna y de un funcionamiento democráticos. 
Las secciones sindicales y los delegados sindicales, se pueden calificar al mismo tiempo como instancias organizativas internas del sindicato y como representaciones externas. Como instancias organizativas internas, tanto la constitución de secciones como la elección de delegados sindicales, que actuarán en representación de los afiliados, manifiestan el ejercicio de la libertad interna de autoorganización del sindicato, formando parte del contenido esencial de la libertad sindical.

De esta manera, los anteriores órganos forman parte del contenido esencial de la libertad sindical, porque a través de ellos el sindicato puede estar presente en los lugares de trabajo y realizar allí sus funciones representativas y ejercer aquellas actividades que permitan la defensa y protección de los propios trabajadores.

La exigencia del art. $7 \mathrm{CE}$ de que tanto la estructura como el funcionamiento de los sindicatos sea democráticos, tiene una importante repercusión en la elección o designación de representantes en las llamadas "elecciones sindicales". Esta condición resulta un elemento imprescindible para el ejercicio de la actividad sindical en libertad, supone que los sindicatos puedan ejercer libremente sus actividades y poner en práctica sin restricciones infundadas sus programas de actuación.

En efecto, de la doble vertiente de las elecciones sindicales destaca no sólo la elección de los representantes de los trabajadores en el centro de trabajo o empresa, sino que dicha elección incide además directamente en la actividad sindical al promover la audiencia de los distintos sindicatos en los órganos de representación unitaria o electiva de los trabajadores. De esta forma, nuestro sistema se puede basar en el criterio de "mayor representatividad" o "suficiente representatividad" de los sindicatos.

Actualmente los sindicatos más representativos en el ámbito nacional son UGT y CC.OO; en el ámbito autonómico ELA-STV y Convergencia Intersindical Gallega. Por otra parte, la asociación empresarial más representativa en nuestro país es la Confederación Española de Organizaciones Empresariales (CEOE), a la que está adherida la Confederación Española de la Pequeña y Mediana Empresa (CEPYME).

Por otro lado, en relación a los empresarios existe una discusión sobre si el asociacionismo empresarial goza de la cobertura del derecho de la libertad sindical 
expresado en el art. $28 \mathrm{CE}$, o si al contrario, se debe situar dentro del derecho general de asociación. Tanto en uno como en otro caso sería objeto de la máxima protección, al encontrar acomodo, también en el segundo caso, en el derecho fundamental de asociación del art. 22 CE.

Por último, la relevancia de la función de los sindicatos y asociaciones empresariales como defensores de los intereses económicos y sociales que les son propios, se manifiesta no sólo en el ámbito nacional, sino también en el marco europeo, en el que existen, por un lado, organizaciones sindicales como la Confederación Europea de Sindicatos (CES) y la Confederación Internacional de Organizaciones Sindicales Libres (CIOLS); y por otro lado, asociaciones empresariales como la Unión de Industrias de la Comunidad Europea (UNICE) y el Centro Europeo de Empresas Públicas (CEEP).

\subsection{Pérdida de fuerza}

Los siete años de crisis económica se han llevado por delante parte de la credibilidad de los sindicatos, que desde que en 2009 alcanzaron su techo en cifras de afiliación no han dejado de perder militantes. CCOO y UGT. A ello hay que añadir la incapacidad de las dos organizaciones mayoritarias para detener la paulatina pérdida de derechos laborales de los últimos años y los casos de corrupción que han afectado a ambas.

Las reformas laborales del PSOE (2010) y, sobre todo, la del PP (2012), respondidas con tres huelgas generales, han dado la puntilla al poder sindical, que ha perdido también el patrimonio de la movilización a favor de otras organizaciones como el $15 \mathrm{M}$ o el movimiento antidesahucios. Conscientes de la situación, ambos sindicatos se aprestan a afrontar cambios para recuperar la influencia perdida.

Los dos sindicatos mayoritarios de nuestro país suman dos millones de afiliados (en torno a un millón cada uno de ellos) y por el camino de la crisis se han dejado otros 400.000. Un problema especialmente grave en un país donde la sindicación es tradicionalmente muy baja, el 18,9\%, por debajo de la media europea y a enorme distancia de los países nórdicos, donde ocho de cada diez trabajadores pertenecen a 
algún sindicato. Pese a ello, siguen siendo la organización social más representativa de nuestro país.

\begin{tabular}{|l|l|l|l|}
\hline País & $\begin{array}{l}\text { Porcentaje de } \\
\text { afiliación }\end{array}$ & País & $\begin{array}{l}\text { Porcentaje de } \\
\text { afiliación }\end{array}$ \\
\hline Dinamarca & $80 \%$ & Alemania & $22 \%$ \\
\hline Finlandia & $74 \%$ & Holanda & $22 \%$ \\
\hline Suecia & $78 \%$ & República Checa & $22 \%$ \\
\hline Noruega & $53 \%$ & Bulgaria & $20 \%$ \\
\hline Bélgica & $55 \%$ & España & $19 \%$ \\
\hline Luxemburgo & $46 \%$ & Hungria & $17 \%$ \\
\hline Italia & $35 \%$ & Eslovaquia & $17 \%$ \\
\hline Irlanda & $35 \%$ & Letonia & $16 \%$ \\
\hline Austria & $35 \%$ & Portugal & $15 \%$ \\
\hline Rumania & $30 \%$ & Polonia & $15 \%$ \\
\hline Eslovenia & $30 \%$ & Lituania & $14 \%$ \\
\hline Grecia & $30 \%$ & Francia & $8 \%$ \\
\hline Gran Bretaña & $28 \%$ & & \\
\hline & & & \\
\hline & MEDIA UE & $23 \%$ & \\
\hline
\end{tabular}

Un estudio realizado en junio de 2015 por la Fundación $1^{\circ}$ de Mayo, de $\mathrm{CCOO}^{10}$ sobre la representación sindical en España señala que las causas del declive afiliativo a partir de 2009 están claramente relacionadas con la crisis. También con el hecho de que los distintos tipos de respuesta sindical a las pérdidas de empleo y al deterioro de los salarios y de las condiciones de trabajo no han tenido éxito, salvo en casos limitados (huelgas locales y victorias parciales en los tribunales).

\footnotetext{
${ }^{10}$ Véase Otaegui, A (2012), "Participación Sindical en Europa y representación de los trabajadores en tiempos de crisis", Fundación $1^{\circ}$ de Mayo, p. 6 en:

http://www.1 mayo.ccoo.es/nova/files/1018/ParticipacionSindical.pdf
} 


\section{La reducción de los afiliados}

Más de cuatro millones de parados, trabajo precario y mal pagado son condiciones que, sobre el terreno, parecen propicias para el crecimiento del sindicalismo pero, por el contrario, juegan a la contra. Más de la mitad de los casi 15 millones de asalariados de nuestro país tienen contratos precarios, temporales o a tiempo parcial, y un trabajador que tiene un contrato de tres meses o de tres semanas, que sabe que su continuidad en la empresa está en el aire, por muchas razones que tenga para protestar no lo va a hacer. De manera que el paro y la inestabilidad no juegan a favor, sino en contra de la pulsión reivindicativa, al contrario de lo que en una primera lectura pudiera parecer. Una situación que ha sido deliberadamente potenciada con la reforma laboral de 2012, tremendamente desreguladora, que ha debilitado a los sindicatos.

Una opinión que comparte Fernando Lezcano: "Es cierto que se dan las condiciones aparentes para que el sindicato sea más necesario que nunca, pero la realidad es que cuando un trabajador se queda en paro, antes que de otras cosas prescinde de la cuota sindical. Además, opera otro fenómeno determinante, y es que el 96\% de las empresas españolas tiene menos de 25 personas y en ellas se concentra la contratación a temporal o a tiempo parcial, con salarios muy bajos, y eso desincentiva la afiliación porque los trabajadores tienen miedo a significarse" ${ }^{" 1}$. Distintos estudios demuestran que, efectivamente, la representación sindical aumenta considerablemente conforme aumenta el tamaño de la empresa y es menor, e incluso inexistente, cuanto más pequeña es la compañía. Además, a aquellas con menos de diez empleados no se les permite celebrar elecciones sindicales (la inmensa mayoría, en torno a 920.000 en 2012, más del doble de aquellas en las que sí se pueden convocar comicios), y sólo las que tienen más de 50 pueden elegir un comité de empresa.

Hay una gran proporción de trabajadores con contratos temporales que no están representados por los sindicatos. Todos los estudios académicos demuestran que hay muy pocos empleados temporales afiliados. Cuando hablas con ellos para conocer sus razones te dicen que los sindicatos sólo defienden a los trabajadores con contratos

\footnotetext{
${ }^{11}$ FONSECA, C., "Sindicatos. Renovarse o morir", Revista sobre la actualidad en España y en el mundo, Cambio 16 (07/3/2016), recuperado el 29 de junio de 2016 de: http://www.cambio16.com/reportajes/sindicatos-renovarse-o-morir/
} 
estables, y lo cierto es que de los que encadenan trabajos precarios y periodos de paro los sindicatos pasan.

"Lo esencial es saber organizar, afiliar y representar bien a esa gran masa de trabajadores con empleo temporal, precario, a tiempo parcial no voluntario o parados dice el informe de la Fundación $1^{\circ}$ de Mayo-. Y aquí es donde hemos fallado, no por falta de voluntad, sino porque no hemos sabido cómo hacerlo". ${ }^{2}$

Las crisis económicas son una pésima noticia para los sindicatos. La excepción a la regla fue la Gran Depresión de los años 30 en Estados Unidos, donde ganaron mucha fuerza porque fueron capaces de responder a ella como un gran movimiento social. El sindicalismo está en crisis en otros muchos países, no sólo en España, a ello contribuyen otros factores, y no sólo la situación económica. Hay que tener en cuenta que ha habido un cambio significativo de la estructura ocupacional, con el declive de la antigua industria, en la que el sindicato estaba muy arraigado, en beneficio de otros sectores menos reivindicativos. Y, además, las reformas laborales, sobre todo la del PP de febrero de 2012, han introducido modificaciones legales que han debilitado la negociación colectiva. Si la fuerza del sindicato está en su capacidad para representar a los trabajadores en la negociación y ésta decae, es normal que le afecte.

La renovación del sindicalismo tiene que hacer frente necesariamente a los retos que plantean los cambios en el trabajo y en las relaciones sociales de producción derivadas de la segunda globalización del capitalismo, ligada a la revolución tecnológica de las TIC. Y adaptarse a las nuevas circunstancias de trabajo para transformarlas. Y para ello, lo esencial es saber organizar, afiliar y representar bien a esa gran masa, que son los trabajadores más explotados (en España más del 50\%), es decir, esos trabajadores con empleo temporal, precario, a tiempo parcial no voluntario o simplemente parados. ${ }^{13}$

Otra forma de renovación del sindicalismo es promover sin perder la autonomía sindical, las alianzas políticas y sociales necesarias para que se produzca un cambio del modelo productivo y político-social, para afrontar revolución tecnológica y

\footnotetext{
${ }^{12}$ Véase Alós, R, Beneyto, P, Jódar, P, Molina, O, Vidal, S (2015), "La Representación Sindical en España", Fundación $1^{\circ}$ de Mayo, p. 10 en: http://www.1 mayo.ccoo.es/nova/files/1018/LibroRepresentacion.pdf ${ }^{13}$ Idem, p. 9
} 
globalización promoviendo marcos jurídicos-políticos justos y democráticos en España, en Europa y en el mundo. ${ }^{14}$

\section{Crisis de credibilidad}

La crisis y el cambio de modelo productivo ha debilitado a los sindicatos, pero además, lo que sufre el sindicalismo es una crisis de credibilidad como consecuencia de los casos de corrupción que hemos vivido. Si comparamos la afiliación con el número de asalariados la realidad demuestra que guarda una estrecha relación, y que si hay menos afiliados es porque hay menos asalariados, no porque los trabajadores les hayan retirado de manera masiva su confianza. Lo que sí hay que reconocer es una pérdida de la representación de los dos grandes sindicatos porque hay cosas que no se han hecho bien y hay que cambiar. Hasta el pasado mes de diciembre UGT y CCOO habían perdido 22.000 delegados en relación a 2011, con un descenso del 16,7\%. Una reducción en prácticamente todos los sectores productivos y, salvo contadas excepciones, en todas las comunidades autónomas, según datos de UGT. ${ }^{15}$

El sindicalismo vive una gran crisis pero sigue siendo un instrumento insustituible para defender las condiciones de trabajo y de vida de los trabajadores y también una herramienta necesaria para superar el modelo neoliberal y la colusión de intereses entre las élites económicas y políticas que lo sustentan. Para construir sociedades mucho más justas, igualitarias y democráticas.

Los sindicatos están en crisis en la medida en que lo están todas las instituciones económicas, políticas y representativas porque estamos ante un cambio de modelo económico productivo y de representatividad. Para muchos asalariados los sindicatos son irrelevantes y esto es una tragedia dada la situación socioeconómica que España vive en este momento. El gran peligro hoy es que los sindicatos caigan en la casi irrelevancia.

\footnotetext{
${ }^{14}$ Idem, p. 10

${ }^{15}$ FONSECA, C., "Sindicatos. Renovarse o morir", Revista sobre la actualidad en España y en el mundo, Cambio 16 (07/3/2016), recuperado el 29 de junio de 2016 de:

http://www.cambio16.com/reportajes/sindicatos-renovarse-o-morir/
} 
Las causas del declive afiliativo del sindicalismo en España a partir del 2009 están claramente relacionadas con la crisis y pérdida de empleo y con los diferentes tipos de respuesta sindical a las masivas pérdidas de empleo y al deterioro de los salarios, las condiciones de trabajo, las prestaciones sociales y los servicios públicos no han tenido éxito. ${ }^{16}$

Ha habido pérdida de densidad sindical respecto del total de la población activa pero no de densidad sindical respecto a la población activa asalariada ocupada.

Según sindicalistas es erróneo pensar que conforme el empleo se fuera recuperando la tendencia revertirá. En primer lugar, porque las políticas de gestión neoliberal de la crisis han dejado un pesado lastre, con pretensión de que sea permanente, y que afecte a muchos aspectos de la actividad sindical y en particular a su núcleo básico, la negociación colectiva. Y la historia nos indica que el sindicalismo no ha podido progresar en términos de afiliación, densidad sindical y poder contractual en marcos políticos y sociales que hayan sido hostiles de un modo prolongado. ${ }^{17}$

\section{REPRESENTATIVIDAD SINDICAL}

La representatividad sindical hace alusión a que la acción del sindicato es general, para todos los trabajadores y no únicamente para los propios afiliados en sentido estricto, y cuya función es la propia gobernabilidad de las relaciones laborales, mejorar la eficacia de los convenios colectivos y su grado de cobertura así como de los pactos y la concertación social. También tiene como función la mediación en el control de la conflictividad y su canalización a través de un sistema de reglas de procedimiento. Estas funciones requieren un plus de representatividad.

Los sindicatos más representativos son los que tienen un plus de poder que le ha sido otorgado por el Gobierno, debido a que se considera que representan a toda la clase

\footnotetext{
${ }^{16}$ Véase Alós, R, Beneyto, P, Jódar, P, Molina, O, Vidal, S, (2015), "La Representación Sindical en España", Fundación $1^{\circ}$ de Mayo, p. 9 en: http://www.1 mayo.ccoo.es/nova/files/1018/LibroRepresentacion.pdf ${ }^{17}$ Idem, p. 10
} 
trabajadora, no solo a sus afiliados. Por lo tanto a la hora de negociar se seleccionan los más representativos:

Hay tres niveles de representatividad :

\subsection{Sindicatos más representativos a nivel de Estado.}

La atribución de esta condición se efectúa a través de doble criterio:

* Audiencia electoral: Tendrán la consideración de más representativos los sindicatos que acrediten una especial audiencia, expresa en la obtención en dicho ámbito, estatal, del 10\% o más del total de delegados de personal, de los miembros de los comités de empresa, y de los correspondientes órganos de las Administraciones Públicas.

* La irradiación de la representatividad desde el nivel estatal a los niveles territoriales y funcionales inferiores, conforme al cual tendrán también la consideración de más representativos los sindicatos o entes sindicales, afiliados, federados o confederados a una organización sindical de ámbito estatal que tengan la consideración de más representativa de acuerdo con el criterio de la audiencia.

La singular posición jurídica que otorga la mayor representatividad sindical a nivel estatal se concentra en que las organizaciones que tengan dicha consideración gozarán de capacidad representativa a todos los niveles territoriales y funcionales para:

- Ostentar representación institucional ante las Administraciones públicas u otras entidades y organismos de carácter estatal o de Comunidad Autónoma que la tengan prevista.

- Ejercer el derecho a la negociación colectiva en los términos previstos en la LET, de eficacia personal general.

- Participar como interlocutores en la determinación de las condiciones de trabajo en las Administraciones públicas a través de los oportunos procedimientos de consulta o negociación.

- Participar en los sistemas no jurisdiccionales de solución de conflictos de trabajo. 
- Promover elecciones para delegados de personal y comités de empresa y órganos correspondientes de las Administraciones públicas.

- Obtener cesiones temporales del uso de inmuebles patrimoniales públicos en los términos que se establezcan legalmente.

- Cualquier otra función representativa que se establezca.

\subsection{Sindicatos más representativos a nivel de Comunidades Autónomas.}

* Audiencia electoral: Serán más representativos los sindicatos de Comunidad Autónoma que acrediten en dicho ámbito una especial audiencia expresada en la obtención de, al menos, el 15\% de los delegados de personal y de los representantes de los trabajadores en los comités de empresa, y en los órganos correspondientes de las Administraciones públicas, siempre que cuenten con un mínimo de de 1500 representantes y no estén federados o confederados con organizaciones sindicales de ámbito estatal.

* La Irradiación de la representatividad, que tendrán la consideración de más representativos los sindicatos o entes sindicales afiliados, federados o confederados a una organización de ámbito de Comunidad Autónoma que tenga la consideración de más representativa, de acuerdo con el criterio señalado de la audiencia.

* Los sindicatos más representativos a nivel de Comunidad Autónoma gozan de capacidad representativa para ejercer en el ámbito específico de su Comunidad Autónoma idénticas funciones y facultades a las atribuidas legalmente a los sindicatos más representativos a nivel estatal, así como la capacidad para ostentar representación institucional ante las Administraciones públicas u otras entidades u organismos de carácter estatal.

\subsection{Sindicatos más representativos en un ámbito específico.}

Lo son quienes, no teniendo la consideración de más representativos, a nivel de Estado o de Comunidad Autónoma, hayan obtenido en un ámbito territorial y funcional 
específico el $10 \%$ o más de delegados de personal y miembros de comité de empresa y de los correspondientes órganos de las Administraciones públicas.

Estos sindicatos estarán legitimados para ejercer, en dicho ámbito funcional y territorial, las siguientes funciones y facultades:

- La negociación colectiva en los términos previstos en la LET.

- La participación como interlocutores en la determinación de las condiciones de trabajo en las Administraciones Públicas, a través de los oportunos procedimientos de consulta o negociación.

- La promoción de elecciones para delegados de personal y comités de empresa y órganos correspondientes de las Administraciones Públicas.

- Cualquier otra función representativa que se establezca.

- Representación institucional ante las Administraciones Públicas.

- Ni la obtención d cesiones temporales del uso de inmuebles patrimoniales públicos. Aunque el Tribunal Constitucional dice que estos sindicatos más representativos si tienen derecho a esto.

La irradiación de la representatividad quiere decir que si un sindicato de transportistas de Burgos se afilia a un sindicato que tiene mayor representatividad se le irradia su mayor representatividad, pero solo para su aplicación en Burgos.

\subsection{Conflictividad surgida en la interpretación de los conceptos (entre Estado y CCAA)}

Se producen conflictos entre Estado y Comunidades Autónomas por cuestiones de competencia:

\section{Conflictos positivos de competencia}

Estos conflictos oponen al Estado con una o más Comunidades Autónomas o a dos o más Comunidades Autónomas entre sí. El Gobierno o los órganos ejecutivos de las Comunidades Autónomas pueden promoverlos cuando consideren que una disposición, 
resolución o acto sin valor de ley de una Comunidad Autónoma o del Estado, o la omisión de tales disposiciones, resoluciones o actos, no respeta el orden constitucional de competencias establecido en la Constitución, en los Estatutos de Autonomía o en las leyes orgánicas dictadas para delimitar las competencias entre el Estado y las Comunidades Autónomas.

El Gobierno puede formalizar directamente ante el Tribunal Constitucional un conflicto positivo de competencia o hacer uso del previo requerimiento de incompetencia a la Comunidad Autónoma para que derogue o anule el acto o disposición que considera que vulnera las competencias estatales. El plazo para formalizar directamente el conflicto o hacer uso del requerimiento de incompetencia es el de dos meses desde la publicación o comunicación del acto o disposición viciado de incompetencia. En el caso de que la Comunidad Autónoma requerida no atienda el requerimiento de incompetencia en el plazo de un mes, el Gobierno dispone del plazo de un mes, a contar desde la notificación del rechazo del requerimiento o desde el término del plazo del que dispone la Comunidad Autónoma requerida para contestarlo, para plantear el conflicto ante el Tribunal Constitucional, certificando el cumplimiento infructuoso del requerimiento de incompetencia y alegando los fundamentos jurídicos en los que sustenta su pretensión. ${ }^{18}$

Los órganos ejecutivos de las Comunidades Autónomas, antes de formalizar el conflicto de competencia ante el Tribunal Constitucional, deben requerir motivadamente, en el plazo de dos meses, al Estado o a la Comunidad Autónoma autora del acto o de la disposición viciado de incompetencia para que lo derogue o anule. De no ser atendido el requerimiento de incompetencia en el plazo de un mes, el órgano ejecutivo de la Comunidad Autónoma dispone del plazo de un mes, a contar desde la notificación del rechazo del requerimiento o desde el término del plazo de que dispone el órgano requerido para contestarlo, para plantear conflicto ante el Tribunal Constitucional, certificando el cumplimiento infructuoso del requerimiento y alegando los fundamentos jurídicos en los que sustenta su pretensión.

\footnotetext{
18 TRIBUNAL CONSTITUCIONAL DE ESPAÑA, competencias, conflictos de competencia en: http://www.tribunalconstitucional.es/es/tribunal/competencias/Paginas/COMPT_05_CC.aspx
} 
El Tribunal Constitucional en el plazo de diez días ha de comunicar al Gobierno o al órgano ejecutivo de la Comunidad Autónoma la iniciación del conflicto, señalándole plazo, que no podrá ser superior a veinte días, para que formule las alegaciones que tuviera por conveniente. La sentencia que resuelva el conflicto declarará la titularidad de la competencia controvertida y acordará en su caso la anulación de la disposición, resolución o acto que originó el conflicto si estuviera viciado de incompetencia. ${ }^{19}$

El Gobierno, en uso de la facultad que le confiere el artículo 161.2 de la Constitución, puede instar en el momento de la formalización del conflicto la suspensión de la disposición, resolución o acto objeto del mismo, lo que determinará la inmediata suspensión de su vigencia, debiendo de pronunciarse el Tribunal Constitucional en el plazo de cinco meses, previa audiencia de las partes, sobre el levantamiento o mantenimiento de la suspensión. En los demás casos, el órgano promotor del conflicto de competencia puede solicitar la suspensión de la disposición, resolución o acto objeto del mismo invocando perjuicios de imposible o difícil reparación y el Tribunal Constitucional libremente puede acordar o denegar la suspensión interesada. ${ }^{20}$

\section{Conflictos negativos de competencia}

Los conflictos negativos de competencia pueden ser planteados por una persona física o jurídica y por el Gobierno frente al órgano ejecutivo de una Comunidad Autónoma.

Cuando un órgano estatal o de una Comunidad Autónoma decline su competencia para resolver cualquier pretensión deducida por una persona física o jurídica, por entender que la competencia corresponde a una Comunidad Autónoma o al Estado o a otra Comunidad Autónoma distinta ante la que se ha formulado dicha pretensión, el interesado, una vez agotada la vía administrativa, puede deducir su pretensión ante el Gobierno o el órgano ejecutivo de la Comunidad Autónoma que la resolución dictada declara competente. Si la Administración solicitada en segundo lugar se inhibe, declina su competencia o no pronuncia decisión afirmativa en el plazo de un mes, el interesado en el plazo de un mes desde la notificación de la declinatoria o si hubiera transcurrido aquel plazo sin haberse dictado resolución expresa, puede acudir al Tribunal

\footnotetext{
${ }^{19}$ Ibídem

${ }^{20}$ Ibídem
} 
Constitucional, solicitando el planteamiento del conflicto. Si el Tribunal entiende que la negativa de las Administraciones implicadas se basa en una interpretación de los preceptos constitucionales o de los Estatutos de Autonomía o de las leyes orgánicas u ordinarias que delimitan los ámbitos competenciales del Estado y de las Comunidades Autónomas declarará mediante Auto planteado el conflicto y, tras dar traslado de dicho Auto al solicitante y a las Administraciones implicadas para que formulen alegaciones, ha de dictar sentencia en la que declarará cuál es la Administración competente. ${ }^{21}$

El Gobierno puede plantear conflicto negativo de competencia cuando habiendo requerido al órgano ejecutivo superior de una Comunidad Autónoma para que ejercite atribuciones de su competencia, sea desatendido su requerimiento por declararse incompetente el órgano requerido o éste continúe con su inactividad. Dentro del mes siguiente al día en que de manera expresa o tácita se haya rechazado el requerimiento del Gobierno, éste puede plantear ante el Tribunal Constitucional el conflicto negativo, debiendo indicar los preceptos constitucionales, estatutarios o legales que obligan a la Comunidad Autónoma a ejercer sus atribuciones. Trasladado el planteamiento del conflicto al órgano ejecutivo de la Comunidad Autónoma para que formule alegaciones en el plazo de un mes, el Tribunal ha de dictar sentencia que ha de contener alguno de los siguientes pronunciamientos: ${ }^{22}$

- a) La declaración de que el requerimiento es procedente, lo que conllevará el establecimiento de un plazo dentro del cual la Comunidad Autónoma deberá ejercitar la atribución requerida;

- b) La declaración de que el requerimiento es improcedente. ${ }^{23}$

\section{FUNCIONES DE LOS SINDICATOS}

Por lo general, en el continente europeo los sindicatos tienen una doble estructura: una horizontal, basada en el territorio y la unión intersectorial, lo que supone una

\footnotetext{
${ }^{21}$ Ibídem

${ }^{22}$ Ibídem

${ }^{23}$ Véase SENTENCIA 198/2014, DE 15 DE DICEMBRE en:

https://www.boe.es/diario_boe/txt.php?id=BOE-A-2015-455
} 
orientación más general, porque se representa a todos los trabajadores de un territorio, lo que a su vez comporta dotar de carácter político a su orientación. Y otra estructura vertical: por sectores de actividad vinculados a cuestiones más directas con el trabajo, tales como salario, contratos de trabajo, condiciones de trabajo, seguridad e higiene y otras materias. La estructura vertical, conocida como federación o sindicato de rama o de categoría, conecta con la representación de los afiliados en el nivel de empresa: la sección sindical (Hyman 1977) ${ }^{24}$. Mientras que el Comité de Empresa es un órgano independiente en el cual habitualmente están representados todos los trabajadores.

Las relaciones entre estas dos estructuras, horizontales y verticales, son en muchas ocasiones complejas y a veces conflictivas entre sí. Además, la dinámica de la propia acción sindical resulta relativamente contradictoria. Por un lado, recurre a la movilización y al conflicto y, por otro lado, necesita del acuerdo, de la concertación y el compromiso. La dinámica sindical consiste en una dinámica continua entre el conflicto y el pacto para gestionar el descontento. ${ }^{25}$

\section{La función de mediación: Teoría de los Incentivos}

Los sindicatos son instituciones que actúan como mediadores en relación entre aquéllos que necesitan vender su fuerza de trabajo y quienes pueden comprarla, éste es un rasgo común de los sindicatos. Asimismo, los sindicatos en los países de capitalismo avanzado desempeñan también una mediación de tipo político, entre los trabajadores, por un lado, y el Estado y los partidos políticos, por otro lado. La influencia y el poder de los sindicatos estriban en su capacidad para cumplir las funciones de mediación en el mercado de trabajo y en la esfera de la política. Ambas funciones pueden ser complementarias y reforzarse recíprocamente; lo que significa que la fuerza del sindicato en el mercado laboral potencia su influencia en la vida laboral y viceversa. Por consiguiente, los sindicatos en cuanto instituciones están interesados en mantener y aumentar su capacidad de mediación entre la esfera del mercado laboral y esfera de la

\footnotetext{
${ }^{24}$ Véase Köhler,H-D y Martín Artiles, A (2007). Manual de la sociología del Trabajo y de las Relaciones laborales. Madrid, Delta.. Capítulo 12, $1^{\circ}$ parte., p. 447

${ }^{25}$ Ibídem
} 
política. En otras palabras, están interesados en ampliar la "cobertura" de sus acuerdos. $^{26}$

La capacidad de mediación depende igualmente de la capacidad de representación y/o representatividad de los sindicatos (que son dos conceptos diferentes, que varía de un país a otro). Esta capacidad de representación no sólo legitima su función, sino que también está relacionada estrechamente con el poder de negociación y mediación ante los empresarios, el Estado y los partidos políticos. Además, no hay que olvidar que también la capacidad de negociación y mediación del sindicato depende también de la aceptación y reconocimiento de la contraparte: los empresarios, el Estado y los partidos políticos. Este reconocimiento como "interlocutor válido" influye en su grado de legitimidad. $^{27}$

En resumen, la capacidad de mediación del sindicato estriba en el aumento de su poder y control de los recursos económicos y políticos que afecta a los trabajadores, al mismo tiempo que sus interlocutores (empresarios, Estado y partidos políticos) aceptan esa función intermediadora. Las funciones del sindicalismo se pueden explicar siguiendo una adaptación del modelo explicativo de James O. Wilson realizada por Lange/Ross/Vanicelli (1991, 296-298) que figura en la lectura $6 .^{28}$

\section{ESPECIAL MENCIÓN A LA FIGURA DEL DELEGADO SINDICAL EN CONTRAPOSCICIÓN AL ENLACE SINDICAL}

\section{Delegado sindical}

Trabajador elegido, por y entre los afiliados al sindicato en la empresa o centro de trabajo. Además de representar a una sección sindical de la empresa, asume funciones de coordinación interna de la sección, así como de su conexión con el sindicato en que

\footnotetext{
${ }^{26}$ Ibídem

27 Ibídem

${ }^{28}$ Véase Köhler,H-D y Martín Artiles, A (2007). Manual de la sociología del Trabajo y de las Relaciones laborales. Madrid, Delta.. Capítulo 12, 1parte, LECTURA 6, Funciones de los Incentivos: trabajadoressindicatos-empresarios- estado., p. (448-449)
} 
se integra. La ley exige para que pueda haber un delegado sindical la concurrencia de dos requisitos: ${ }^{29}$

1) Que el centro de trabajo emplee a más de doscientos cincuenta trabajadores,

2) Que sea una sección sindical perteneciente a un sindicato con presencia en el comité de empresa.

El delegado sindical es el representante, ante el jefe de empresa, de un sindicato. No debe confundirse el delegado sindical con el representante sindical en el comité de empresa.

1. Los delegados sindicales representan a la sección sindical «a todos los efectos» (art. 10.1 L.O.L.S.) ${ }^{30}$. Además, pueden asumir funciones de coordinación de la sección y de conexión de la misma con el sindicato de procedencia.

2. Las secciones sindicales pertenecientes a un sindicato con presencia en los órganos de representación unitaria de los trabajadores estarán representadas por delegados sindicales en aquellas empresas o, en su caso, centros de trabajo (la elección de uno u otro ámbito dependerá de la previa decisión adoptada acerca del ámbito de la sección) que ocupen al menos 250 trabajadores, cualquiera que sea la clase de su contrato, esto es, cualquiera que sea el tipo o modalidad contractual que les vincule con la empresa. Las secciones sindicales cuyo sindicato de procedencia no cumpla el requisito de presencia en los órganos de representación unitaria de los trabajadores o estén constituidas en empresas o centros de trabajo de menos de 250 trabajadores podrán nombrar representantes o portavoces (delegados internos), pero no delegados sindicales como representaciones externas con los derechos reconocidos en la L.O.L.S.

3. El número de delegados sindicales por sección se determina con arreglo a la siguientes reglas cuantitativas (art. 10.2 L.O.L.S.) ${ }^{31}$ :

\footnotetext{
${ }^{29}$ Véase Ley Orgánica $11 / 1985$, de 2 de agosto, de Liberta Sindical, arts. 8 y 10

${ }^{30}$ Ley Orgánica de Libertad Sindical (2012). Legislación Social Básica, artículo 10, p.827

${ }^{31}$ Ibídem
} 
1. a Las secciones sindicales de sindicatos que no hayan alcanzado el 10 por 100 de los votos en la elección del comité de empresa estarán siempre representadas por un solo delegado sindical, con independencia del mayor o menor número de trabajadores en la unidad de referencia.

2. ${ }^{a}$ Las secciones sindicales de sindicatos que hayan obtenido dicho 10 por 100 estarán representadas por un número de delegados sindicales variable en función del número de trabajadores de la empresa o centro de trabajo, de acuerdo con la siguiente escala: de 250 a 750 trabajadores, 1 delegado sindical; de 751 a 2.000, 2; de 2.001 a 5.000, 3, y de 5.001 en adelante, 4. Estas secciones sindicales estarán representadas por el mismo número de delegados sindicales, sin que la obtención de más o menos votos determine ninguna variación numérica al respecto.

4. El número de delegados sindicales es ampliable por acuerdo o convenio colectivo (art. 10.2 L.O.L.S.) ${ }^{32}$.

5. Los delegados sindicales serán elegidos por y entre los trabajadores afiliados al sindicato correspondiente en la empresa o centro de trabajo (art. 10.1 L.O.L.S.). El procedimiento electoral será el establecido en los estatutos del sindicato, correspondiendo a éste la función de controlar su cumplimiento. A pesar del silencio legal, los componentes de la sección deberán dar cuenta del resultado de dicho procedimiento al empresario, el cual no podrá negarse al reconocimiento de los delegados sindicales designados, si la sección sindical cuenta con las exigencias legales para ello.

6. Los delegados sindicales tienen reconocidos unos derechos instrumentales para el ejercicio de su función (en el supuesto de que no formen parte del comité de empresa) (art. 10.3 L.O.L.S.), ya que, de ser así, estos trabajadores ya disfrutan, como representantes unitarios de los trabajadores, de las facultades y garantías establecidas en los arts. 64 y 68 del E.T. y normas concordantes. En cualquier caso, no se dobla el crédito de horas si ya son representantes del personal. Los delegados sindicales que no sean simultáneamente representantes unitarios gozan de las mismas garantías que éstos, así como de los siguientes derechos (art. 10.3 L.O.L.S.): 1. ${ }^{\circ}$ Un derecho de acceso a la 
misma información y documentación que la empresa ponga a disposición del comité de empresa; $2 .^{\circ}$ Un derecho de asistencia a las reuniones del comité de empresa y de los órganos correspondientes en materia de seguridad e higiene, con voz pero sin voto, y 3..$\left.^{\circ}\right)$ Un derecho a ser oídos por la empresa previamente a la adopción de medidas de carácter colectivo que afecten a los trabajadores en general y a los afiliados a su sindicato en particular, y especialmente en los despidos y sanciones de estos últimos ${ }^{33}$.

No hay que confundir al delegado sindical con el delegado de personal, ya que los primeros son órganos de representación unitaria junto con los comités de empresa o juntas de personal en el caso de las administraciones públicas y son elegidos democráticamente por los trabajadores, y los delegados sindicales son personas que la sección sindical de un sindicato presente en la empresa nombra como representante de ese sindicato tras acordarlo en Asamblea. Puede ser miembro del comité de empresa

\section{ÓRGANOS DE REPRESENTACIÓN UNITARIA}

Los órganos de representación unitaria representan a los trabajadores en los centros de trabajo. Estos órganos son:

Delegados de personal: son órganos individuales de representación de los trabajadores que deberán ser elegidos (mediante sufragio libre, personal, secreto y directo) en las empresas o centros de trabajo que tengan menos de 50 y más de 10 trabajadores. Podrá haber un delegado de personal en aquellos centros que cuenten entre 6 y 10 trabajadores si así lo deciden ellos. Procederá constituir un delegado en los centros que tengan hasta 30 trabajadores y 3 delegados en los centros que tengan de 31 a 49 trabajadores. Los delegados de personal ejercerán su función de forma mancomunada, esto es que no puede realizar actos de representación que vinculen a los representados y que las consecuencias paralizantes de exigir en su actividad representativa la concurrencia de la voluntad de todos ellos. ${ }^{34}$

\footnotetext{
${ }^{33}$ Ibídem

${ }^{34}$ Escudero, R, Mercader, J (2005), "Manual Jurídico de los Representantes de los Trabajadores", La Ley, p. 35
} 
Comités de empresa: es el órgano representativo y colegiado del conjunto de los trabajadores de la empresa o centro de trabajo para la defensa de sus intereses constituyéndose en los centros de 50 o más trabajadores. Su composición viene determinada por una escala que oscila de 5 miembros para los centros de 50 a 100 trabajadores, a 75 miembros como máximo, (21 para los centros de 750 a 1000 trabajadores, y de 1000 en delante 2 por cada 1000). Los comités de empresa elegirán de entre sus miembros un presidente y un secretario y elaborarán su propio reglamento de procedimiento que no podrá contravenir lo dispuesto en la ley. ${ }^{35}$

La duración del mandato de los delegados de personal y de los miembros de comités de empresa será de 4 años pudiendo ser reelegidos.

Las competencias de estos órganos de representación son:

- Negociación de convenios colectivos.

- Información y consulta (derecho a ser informados y consultados por el empresario sobre las cuestiones que puedan afectar a los trabajadores).

- Información en materia de contratación laboral.

- Competencias de vigilancia y control (vigilancia del cumplimiento de las normas en materia laboral y control de las condiciones de seguridad y salud y de igualdad de trato y oportunidades).

-Sigilo profesional (uso adecuado y prudente de la información recibida).

Una de las cuestiones más comentadas de la crisis del sindicalismo en España tiene que ver con el modelo de representación que da a los delegados elegidos y a los comités de empresa, competencias muy importantes, superiores en los comités de empresa respecto de las secciones sindicales, como por ejemplo, negociar el convenio de empresa (y teniendo en cuenta la eficacia del convenio colectivo) es una de las causas principales de la debilidad de la densidad sindical en España:

\footnotetext{
${ }^{35}$ Véase Köhler,H-D y Martín Artiles, A (2007). Manual de la sociología del Trabajo y de las Relaciones laborales. Madrid, Delta.. Capítulo 12, $1^{\circ}$ parte, p. 464
} 
¿Para qué afiliarse a un sindicato si ya tengo comité de empresa que puede negociar un convenio y los convenios me beneficiarán pague o no la cuota de afiliación?

Los datos no apuntan a que sea éste el motivo principal de la debilidad afiliativa. Por el contrario, existe una correlación directa entre existencia de representación de los trabajadores y existencia de afiliación sindical. Entre mayor tamaño de empresas, mayor densidad sindical y por tanto mayores competencias de negociación de los representantes de los trabajadores en la negociación colectiva.

Según estudios y gráficos realizados en el 2012 las elecciones sindicales se pueden celebrar en el 21,3\% de las empresas, aunque para representar al 84\% (8 de los asalariados).

Ante todo se observa que el 76,3\% de dichas empresas tienen como máximo 25 trabajadores y un $40 \%$ está en la frontera de los 6 asalariados. La dispersión y la enorme cantidad de pequeña y microempresa es, evidentemente una dificultad para institucionalizar las relaciones laborales. Son las llamadas empresas blancas, que cuentan con más de 5 trabajadores y no cuentan con representación sindical. Estas son el 74,3\% de las empresas en el año 2003, el 79,5\% en el 2007 y el 79,4\% en el 2012 (gráfico 4.12). Es decir, aproximadamente tres de cada cuatro empresas no contaban con representación institucionalizada de los trabajadores en el año 2003, acercándose en 2007 y 2012 a cuatro de cada cinco empresas. Como se observa en el gráfico 4.12, la proporción de empresas blancas ha aumentado considerablemente de 2003 a 2007, y apenas varía en los cuatro años posteriores. En estas empresas se halla poco menos de la mitad de los trabajadores asalariados, excluyendo a los que están en empresas de hasta cinco trabajadores: en el año 2003 el 47,6\% de los trabajadores carece de representación sindical en su empresa. Esta proporción se eleva al 48,9\% en el año 2007 y al 49,0\% en el $2012 .^{36}$

\footnotetext{
${ }^{36}$ Véase Alós, R, Beneyto, P, Jódar, P, Molina, O, Vidal, S, (2015), "La Representación Sindical en España", Fundación $1^{\circ}$ de Mayo, p. 87 en:

http://www.1mayo.ccoo.es/nova/files/1018/LibroRepresentacion.pdf
} 

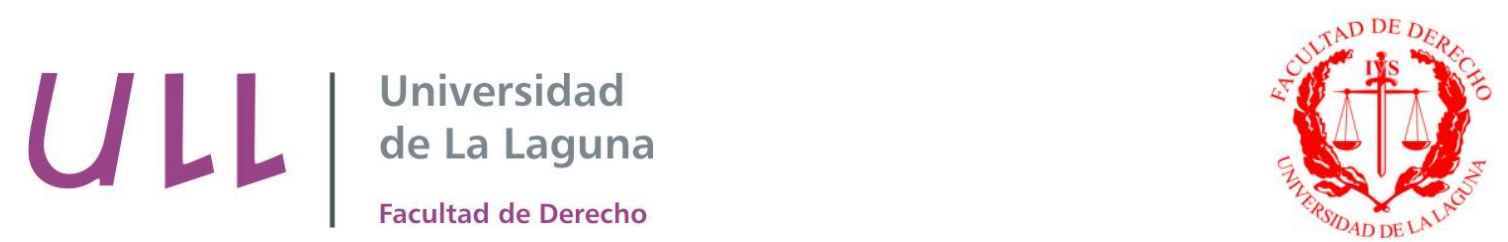

A nivel de CCAA, Madrid, Andalucía, Canarias y Baleares son las comunidades con mayor proporción de empresas blancas. En general en todas las comunidades autónomas este tipo de empresas aumenta de 2003 al 2012. ${ }^{37}$

\section{CONCLUSIONES}

Fundamentalmente, la principal función de los sindicatos es la de defender a los trabajadores frente al empresario, estado o cualquier otra autoridad. Se encargan de la representación de los trabajadores en la negociación colectiva y de velar por el cumplimiento de los acuerdos adoptados. También actúan como representantes del afiliado cuando éste lo requiere, así como actuar como parte en los juicios o reclamaciones, asumiendo la representación del interés social.

Otras funciones asumidas son promover la formación profesional, la propuesta de mejoras en las condiciones laborales de sus trabajadores, control y ejecución de medidas de prevención de riesgos laborales, así como participar en los procesos de contratación de nuevos trabajadores.

Según su propia definición, la misión de cualquier sindicato es conseguir un salario justo para sus trabajadores, conseguir un empleo estable y sin despidos injustos siendo igual tanto para hombres como para mujeres, conseguir mejores condiciones de trabajo, e intentar que el estado implante leyes que mejoren las condiciones económicas y sociales de sus trabajadores.

Como funciones básicas podemos mencionar la simplificación de la negociación colectiva entre empresarios y trabajadores, el establecimiento de un salario mínimo para cada puesto de trabajo o sector ayudando a mejorar la productividad de la empresa, se preocupan en impulsar leyes tanto para la protección del trabajador como de salud laboral. Intervienen en los conflictos laborales como mediadores para poder canalizarlos o encauzarlos y ayudan a las empresas en situación de crisis a buscar nuevas soluciones que no sean los despidos.

\footnotetext{
${ }^{37}$ Idem, p.89
} 


\section{ULL}

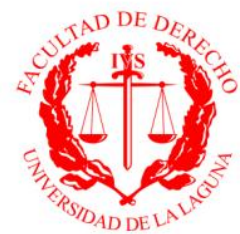

Los sindicatos llevan a cabo la negociación colectiva con las empresas y con el estado para llegar a acuerdos laborales en relación al salario, protección frente al despido, jornada laboral, etc. y todo ello beneficia tanto a los trabajadores que están afiliados al sindicato como a los que no. Por ello, los acuerdos laborales llevados a cabo, benefician a todos los trabajadores, pero solo los costean los trabajadores afiliados al sindicato. Una solución sería que una parte del salario del trabajador fuese destinado a la financiación de los sindicatos mediante un impuesto. Sería una forma más justa de que todo se beneficiasen del mismo modo, y así no tener que llegar al punto de satisfacer en mayor medida las necesidades de los afiliados que de los no afiliados, obligándoles al fin y al cabo a tener que afiliarse al sindicato para poder obtener esos beneficios.

Esto hace que las tasas de afiliación sindical en España y la financiación por parte del Estado a los sindicatos sea una de las más bajas en toda Europa.

Los países con mayor nivel de afiliación sindical son los nórdicos de Europa, como Islandia, Finlandia, Dinamarca, Suecia y Noruega, puesto que llevan a cabo políticas como las anteriormente mencionadas.

A lo largo de las distintas confrontaciones electorales han disminuido el número de delegados sindicales independientes. $\mathrm{La}$ representación sindical se ubica fundamentalmente en las empresas de más de 50 trabajadores (en torno al 60\%). Es decir la mayoría de los delegados forman parte de Comités de Empresa. En otras palabras el principal problema de la representatividad de los sindicatos estriba en su dificultad para obtener representantes en las pequeñas empresas, a lo que se deben añadir las dificultades enormes para representar al amplio colectivo de trabajadores con contratos temporales. Los delegados sindicales son fundamentalmente trabajadores con empleo estable, masculinos y del segmento de población comprendido entres los $30 \mathrm{y}$ 49 años y ubicados en el segmento primario del mercado de trabajo. Por el contrario los trabajadores del segmento secundario apenas están representados, como tampoco lo están los de economía sumergida y los trabajadores temporales. Por lo tanto si no consideramos a los mencionados colectivos (y solo tenemos en cuenta a los trabajadores del sector primario con empleo estable) entonces podemos decir que la representatividad electoral es alta y fuertemente legitimada, cuando la realidad no es esa. 
Si añadimos que el desprestigio de las organizaciones de los trabajadores se ha agudizado con la crisis económica y con la pérdida de credibilidad hacia estas organizaciones, vemos que el panorama sindical actual se tambalea de un modo bastante preocupante.

Lo que sufre el sindicalismo es una crisis de credibilidad como consecuencia de los casos de corrupción que hemos vivido, pero si comparamos la afiliación con el número de asalariados la realidad demuestra que guarda una estrecha relación, y que si hay menos afiliados es porque hay menos asalariados, no porque los trabajadores nos hayan retirado de manera masiva su confianza. Lo que sí hay que reconocer es una pérdida de la representación de los dos grandes sindicatos porque hay cosas que no se han hecho bien y hay que cambiar. Ahora no les queda más que afrontar cambios para recuperar la influencia perdida. La misión de los sindicatos en la actualidad supone renovarse o morir.

\section{BIBLIOGRAFÍA}

Véase Alós, R, Beneyto, P, Jódar, P, Molina, O, Vidal, S, (2015), "La Representación Sindical en España", Fundación $1^{\circ}$ de Mayo, p. 87 en:

http://www.1mayo.ccoo.es/nova/files/1018/LibroRepresentacion.pdf

Álvarez Cuesta, H, "Puntos críticos y alternativas a las elecciones sindicales y a la mayor representatividad"

CIVITAS. Biblioteca de Legislación. "Legislación Social Básica (Trigésima primera edición 2012)": Constitución Española de 27 de Diciembre de 1978, Ley del Estatuto de los Trabajadores, Ley Orgánica de Libertad Sindical LOLS

Escudero, R, Mercader, J (2005), "Manual Jurídico de los Representantes de los Trabajadores", La Ley

Fonseca, C., "Sindicatos. Renovarse o morir", Revista sobre la actualidad en España y en el mundo, Cambio 16 (07/3/2016), recuperado el 29 de junio de 2016 de:

http://www.cambio16.com/reportajes/sindicatos-renovarse-o-morir/ Köhler, H-D (1995), "El movimiento sindical en España. Transición democrática, regionalismo, modernización económica", Madrid, Fundamentos 

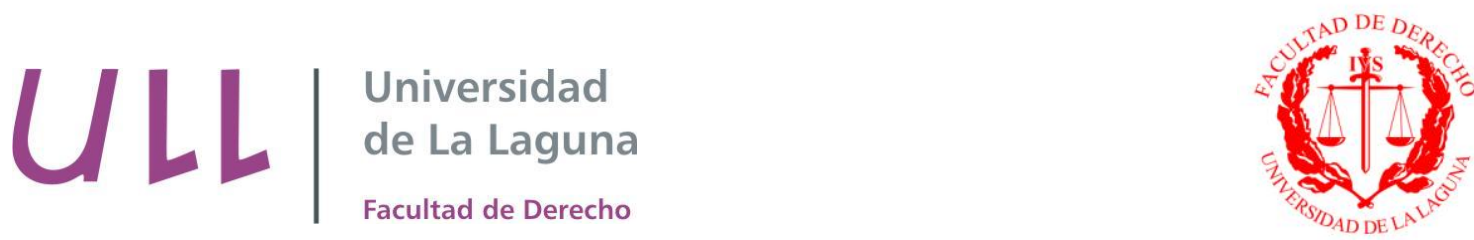

Köhler,H-D y Martín Artiles, A (2007). Manual de la sociología del Trabajo y de las Relaciones laborales. Madrid, Delta.. Capítulo 12, $1^{\circ}$ parte

Köhler,H-D y Martín Artiles, A (2007). Manual de la sociología del Trabajo y de las Relaciones laborales. Madrid, Delta.. Capítulo 12, $1^{\circ}$ parte, LECTURA 6, Funciones de los Incentivos: trabajadores-sindicatos-empresarios- estado

Otaegui, A (2012), "Participación Sindical en Europa y representación de los trabajadores en tiempos de crisis", Fundación $1^{\circ}$ de Mayo, p. 6 en: http://www.1mayo.ccoo.es/nova/files/1018/ParticipacionSindical.pdf

SENTENCIA 198/2014, DE 15 DE DICEMBRE en:

https://www.boe.es/diario_boe/txt.php?id=BOE-A-2015-455

TRIBUNAL CONSTITUCIONAL DE ESPAÑA, competencias, conflictos de competencia en:

http://www.tribunalconstitucional.es/es/tribunal/competencias/Paginas/COMPT_05_CC .aspx 